\title{
GCU
}

Glasgow Caledonian

University

University for the Common Good

\section{Parental participation in statutory child protection intervention in Scotland}

Jackson, Sharon; Kelly, Lynn; Leslie, Brian

Published in:

British Journal of Social Work

DOI:

$10.1093 /$ bjsw/bcw090

Publication date:

2017

Document Version

Author accepted manuscript

Link to publication in ResearchOnline

Citation for published version (Harvard):

Jackson, S, Kelly, L \& Leslie, B 2017, 'Parental participation in statutory child protection intervention in Scotland', British Journal of Social Work, vol. 47, no. 5, pp. 1445-1463. https://doi.org/10.1093/bjsw/bcw090

\section{General rights}

Copyright and moral rights for the publications made accessible in the public portal are retained by the authors and/or other copyright owners and it is a condition of accessing publications that users recognise and abide by the legal requirements associated with these rights.

Take down policy

If you believe that this document breaches copyright please view our takedown policy at https://edshare.gcu.ac.uk/id/eprint/5179 for details of how to contact us. 
Title

Parental Participation in Statutory Child Protection Intervention in Scotland

\section{Authors}

Sharon Jackson, PhD, BA(Hons), Senior Lecturer in Social Work, Department of Psychology, Social Work and Allied Health Sciences, Glasgow Caledonian University

Lynn Kelly, DEd, MA(Hons), MSc, Lecturer in Social Work, School of Education and Social Work, University of Dundee

Brian Leslie, BA(Hons), CQSW, Lecturer in Social Work, School of Education and Social Work, University of Dundee

\section{Corresponding Author}

Sharon Jackson, BA(Hons), PhD, Senior Lecturer in Social Work, Department of Psychology, Social Work and Allied Health Sciences, Glasgow Caledonian University, Glasgow, Scotland, G4 0BA, T: +44 (01)413 3313953 E: Sharon.Jackson@gcu.ac.uk

\section{Funding Bodies}

The funding agency shall remain anonymous. 


\title{
Title
}

Parental Participation in Statutory Child Protection Intervention in Scotland

\begin{abstract}
In recent years there has been an increasing interest in understanding parental participation in the processes that characterise statutory child protection intervention. In part, this reflects a shift in thinking across western child protection systems, which has recognised that active parental involvement in intervention is more likely to lead to better outcomes for children at risk of abuse and / or neglect and a repositioning of child protection practices within broader discourses of service user participation. In this paper we present the findings of a small scale qualitative study which explored the experiences of twelve parents who were, at the time of the study, subject to statutory child protection intervention measures in Scotland. Parents reported intervention experiences as simultaneously negative and positive. The early stages of intervention and child protection case conferences were experienced as particularly distressing and confusing. The importance of the client-worker relationship emerged as central to meaningful participation and positive outcomes.
\end{abstract}




\section{Introduction}

In recent years there has been an increasing interest in understanding parental participation in the processes that characterise statutory child protection intervention. In part, this reflects a shift in thinking across western child protection systems which has recognised that active parental involvement in intervention is more likely to lead to better outcomes for children at risk of abuse and / or neglect (Saint-Jacques et al., 2006) and a repositioning of child protection practices within broader discourses of service user participation (Corby et al., 1996; Healy \& Darlington, 2009). As a consequence, there has been a growth in the number of studies which have sought to explore parental experiences of statutory child protection intervention through a participatory lens. In this paper we present the findings of a small scale qualitative study which adds to the expanding evidence base in this area. The study being reported explored through qualitative interviews the experiences of twelve parents who were, at the time of the study, subject to statutory child protection intervention in Scotland.

\section{Participation and Child Protection}

The participation of service users has become increasingly embedded in the legislative, policy and practice frameworks of western child protection systems (Healy \& Darlington, 2009, Healy, et al., 2012). However, the participation of service users in social work processes has a complex aetiology in differing and competing ideologies of participation which overlap with wider social, political and economic forces. Two major philosophies of participation have however emerged to dominate thought in this area. These have evolved through a complex interweaving of rights-based discourses underpinned by concepts of social justice and self-determination and modernist constructs of consumerism that position service 
users as customers (Gallagher and Smith, 2010). While the ideas contained within these discourses connect and are framed in more complex ways with international human rights agendas, service user participation has emerged as one of the central motifs of UK government welfare programmes (Warren, 2007). However, critics have argued that discourses of service user participation are primarily focused on creating economic efficiencies within the welfare marketplace (Begum, 2006) and not with issues of social justice or rights. Strongly associated with the managerialist agenda of the 'new right' conservative governments of the 1980s and early 1990s, and handed down to successive labour governments, service user participation has been articulated as leading to more informed service development, increased effectiveness and improved outcomes.

Within Scotland, the rights of parents (and children) to participate in the decision making practices of child protection intervention is legislated for within The Children (Scotland) Act 1995. Other directives and sets of guidance embed this core principle. For instance, the National Guidance for Child Protection in Scotland (Scottish Government, 2014) in outlining the principles for effective practice, situates parental participation as fundamental to achieving good working relationships with families. Operationally, this is translated within the guidance as ensuring that families are listened to, that their views are respected and considered in decision making, that their privacy and dignity is respected and that processes, decisions and actions are explained sensitively taking into account the particular communication needs of individuals.

While Scottish Government legislation and guidance for child protection reflects consumerist and rights based participatory discourses, on an international basis, the concept of participation resonates strongly with core social work values and principles which emphasise 
the role of the social worker in promoting individual rights, self-determination and empowerment through working 'with' service users (Asquwith et al., 2005). Indeed, promoting the participation of service users features as a core principle within the ethical codes of practice for social workers both nationally and internationally (British Association of Social Workers 2012; International Federation of Social Workers, 2004). For example, The International Federation of Social Workers (2004) in their Statement of Ethical Principles states that:

"Social workers should promote the full involvement and participation of people using their services in ways that enable them to be empowered in all aspects of decisions and actions affecting their lives."

The concept of participation has, however, been recognised as problematic in child protection contexts. In a notable critique of participation in child protection contexts, Healy (1998:900) identifies that the transference of the concept of participation from other areas of practice which are, 'markedly dissimilar to child protection work', have placed limitations on participation. Most crucially, the particular complexities inherent in an area of practice which draws on the use of statutory power have been somewhat eclipsed. While Healy (1998) maps out a range of constraints which limit participatory practice, the inherent power inequalities between involuntary service users and professionals is a central feature. Drawing on French and Raven's (1959) seminal analysis of power, Ryburn (2006:87) presents the argument thus:

'In the child protection field professionals almost always possess the additional capacity to impose their will as a consequence of a mandate granted to them in legislation. Thus, within the constraints imposed by the bureaucracy in which they work, they enjoy a power to reward, to coerce, to make legitimate or to punish.' 
Hence, it has been argued that translating participatory ideas and associated concepts such as partnership and empowerment into child protection contexts is inherently problematic (Corby et al., 1996). Given the nature and concerns of child protection it is not difficult to grasp the difficulties of embedding participatory practices where the rights of children to be protected from harm are continuously being balanced and brought into conflict with the rights of parents. Indeed, it has been argued that as conflict is inevitable, given the adversarial nature child protection, that professionals can only work with restrictive notions of participation (Corby et al., 1996).

Research has however demonstrated that practitioners are committed to the values that underpin participation (Bell, 1999). The active involvement of service users in decision making is also considered to be a more humane, ethical and effective model of practice (Corby et al., 1996; Buckley et al., 2011). However, studies of participation have revealed that service users are generally marginalised within child protection process with restricted opportunities for participation (Barford and Wattam, 1991; Barford, 1993; Corby et al., 1996). In some instances, studies report this to be the case whilst simultaneously reporting strenuous efforts by professionals to embed participatory practices (Bell, 1999). While this might suggest that the concept of participation should be understood as limited within child protection contexts, some critics have argued for a re-articulation of the concept which recognises the complexities of child protection work. Healy (1998) for example, argues for a poststructuralist approach to participation that is grounded in a Foucauldian analysis of power. Such an approach she suggests embraces the tensions and complexities of child protection work by understanding power as a relational concept within the worker-client 
nexus. This recognises first, that clients are not necessarily passive or compliant and second, that the use of power can be constructively used.

\section{Parental Experiences of Intervention}

Notwithstanding the recognised difficulties with the concept of participation, existing research has been argued to paint a somewhat 'blurry picture' of how the processes of intervention are experienced (Dumbrill, 2006:28) and, at worst, a 'generally uncomplimentary picture' (Dale, 2004:137). While there are some indications amongst studies that parents are perhaps better informed about processes, are receiving better information and are more involved in decision making, for the most part, research suggests that parents have mixed experiences. There is, as Wrennall (2010:309) reports, 'extensive evidence of harm to families' with researchers reporting that intervention is experienced as more traumatising than the conditions that led to it (Cooper et al., 2003). At the same time there are studies such as Buckley et al's (2011) and Woolfson et al's (2010) which report that intervention may be simultaneously experienced as distressing and supportive, characterised by both negative experiences and positive outcomes.

Insensitive and unnecessarily invasive practices have been identified as adding to the distress parents experience (Davies, 2011). Moreover, many researchers report parental narratives of distress that are interwoven with accounts of authoritative modes practices. A recent study by Smithson \& Gibson (2016) for instance, reveals the ways in which some parents identified themselves as lacking influence in decision making processes due to the power differences that existed between themselves and professionals. Professionals were reported to have used 
their professional authority in decision making forums such as case conferences to belittle, attack and silence the voices of parents. Parents also reported feeling that they were not listened to, that they lacked information about processes, how decisions were reached, and why actions and plans changed. The study authors acknowledge that such findings are not new, however, they also caution that perhaps the practices in their study site were more authoritarian in orientation than others. Nonetheless, it could be inferred from the findings of such studies that modes of practice which create the conditions for participation are not routinely accomplished.

Studies have identified, that the creation of good relationships between professionals and families can alleviate some of the negative consequences experienced by parents (Buckley et al., 2011; Bilson, 2002). Professional qualities and skills that lead to the creation of a 'helping alliance' between professionals and parents have been highlighted (Maiter et al, 2006:182). Here, compassion, empathy, helpfulness, supportiveness, honesty, the ability to listen and so forth, are considered essential professional attributes (Kadushin and Kadushin, 1997; Trotter, 2002). These coupled with skills in bringing clarity to the professional role, the nature of intervention, the parameters of confidentiality and being honest about professional authority are considered pivotal to the development of positive worker-client relationships and the potential for good outcomes (Trotter, 2002). These are the same or similar qualities to those highlighted within sets of professional guidance as necessary for participation (Scottish Government, 2014). 


\section{Study Methods}

\section{Aims and Objectives}

This study was underpinned by the funding agency's commitment to seek the participation of services users in the design and delivery of services through (a) exploring parents' experiences as service recipients and the participatory dimensions of this and (b) actively engaging in the findings of this study to improve services. In doing so, the study explored parents' understanding of processes, support, communication and information practices and whether parents felt they could express their views and have these heard. The study also sought parental views on the outcomes of the support they received and, where relevant, what could be changed or done differently.

\section{Study Sample}

Eleven parents participated in this study. Of these seven were mothers and four were fathers. At the time of interview all parents were subject to statutory child protection measures. Within Scotland, each local authority maintains a register of children who are considered to be at risk of harm. A child's name may be entered onto the register under one or more of five categories: physical abuse, physical neglect, sexual abuse, failure to thrive or emotional abuse. All parents had children who were currently registered and some children had been removed from parental care. One grandfather participated in this study as the main carer for two children who had been removed into his guardianship. The grandfather and five of the parents were interviewed individually with a further three interviews being held with couples. 
It is not uncommon for researchers and / or funding agencies to censor information about participants or research sites to protect the confidentiality and anonymity of participants and other stakeholders (Bulmer, 2001). This is often connected to concerns about harm to participants (Lee, 1993). In reporting our findings we have been cognisant of the funding agency's concerns around the inclusion of participant details that may compromise the limits of confidentiality. We acknowledge that this constrains what we can report and reduces analytical nuance. It is, however, recognised that parents involved in the child protection system are affected by multiple chronic stressors (Dale, 2004). The parents in our sample were not markedly different in this respect. Issues connected to poverty and deprivation, domestic violence, substance misuse, mental health issues, disability, unstable relationships, physical health and wellbeing issues and adverse childhood experiences and so forth were present in various and multiple combinations.

\section{Sampling Procedures, Access and Consent}

We worked in partnership with the local authority to identify a sample and negotiate access and consent. Stratification of the sample through random sampling of participants was not possible. Initial attempts to do so through an anonymised list drawn from the child protection register proved problematic. We drew on the experiences of professionals who knew the parents' and the circumstances of particular families. Therefore some families who were initially selected through randomisation were filtered out because it was deemed inappropriate to approach them. Some parents declined to participate in this study for reasons unknown to us. We therefore had to proceed with those who were willing to participate. 
Consent processes with vulnerable populations are recognised as requiring acute sensitivity with regards to the capacity of individuals to fully understand the purposes of a study (Bosk, 2002). Moreover, individuals who feel disempowered may be fearful of perceived negative consequences if they do not wish to participate or they may inappropriately acquiesce to requests (Fisk \& Wigley, 2000; Warren, 2002). In attending to these issues, recruitment and consent processes were conducted by the main professional working with the parent/s. For the most part, these procedural decisions appeared to have worked well however there were at least two occasions where in spending time with participants prior to interview, the interviewing researcher felt that parents' understanding of the study remit was weak. In these instances steps were taken to acquire informed consent that we considered was ethically accomplished.

\section{Reflexivity and Ethical Sensitivity}

Akin, to others we consider the concept of participation as problematic in child protection contexts. We were mindful that, such a stance can impose a 'powerful conceptual grid upon data' (Sensing, 2011:202). Consequently, we invoked an active 'reflexive bracketing' of our assumptions to reduce analytical blindness. Moreover, the participation of involuntary clients in research is also difficult to operationalise. It is essential that researchers are ethically and procedurally sensitive and attuned to the complex and interweaving ways in which participants could be considered 'vulnerable' throughout the research process (Liamputtong, 2007). Research of this kind is also profoundly sensitive (Liamputtong, 2007). It asks participants to share experiences and feelings that are the deeply personal and emotionally demanding to revisit. In considering these issues a number of pre-empirical procedures and decisions were constructed. Firstly, we considered the importance of our respective skills 
and experience. We decided that the interviews should be conducted by a member of the research team who was a registered social worker with extensive child protection experience. We considered that she had a stronger repertoire of context relevant professional skills, expertise, knowledge and experience to conduct the interviews with due care and sensitivity.

\section{Data Recording and Analysis}

Permission to digitally record interviews was sought and granted from all participants. Due to the sensitivity of the research we transcribed the interview material ourselves. Information identifying participants, professionals or the research site were removed during transcription. Data relating to this study have been treated in accordance with the requirements of the Data Protection Act (1998). All data were transported on encrypted and password protected devices and uploaded to secure institutional servers.

As a qualitative exploration, this study was interested in understanding the experiences of parents through a participatory lens hence the aims and objectives of the research framed our analysis. However, conceptual co-ordinates for our analysis were also derived from our understanding of the concept of participation and our review of the theoretical and empirical literature connected to this. Our approach to data analysis can be described as thematic. Here, we define thematic analysis as a descriptive approach for 'identifying, analysing and reporting themes within the data' (Braun \& Clarke, 2006:79). 


\section{Findings}

\section{The Early Stages of Intervention}

Parents experienced the initial stages of intervention as overwhelming and distressing. Reflecting on this time in their lives was emotionally difficult for parents. One mother cried when she stated:

'It was hard. It was like my world had ended.' Mother

This mother had experienced one of her children being removed into the care of their grandmother. For a parent this is traumatic, shocking and sometimes unexpected. Parents spoke about feeling ashamed, embarrassed and confused:

'I felt like scum...I felt embarrassed...I felt ashamed of myself...it's a bad thing that social work have to come once a week to make sure kids are alright...I didn't understand it all how they got on the register [child protection register]. What is the register? It was a long time ago...so I didn't understand. ..It didn't feel real to me...when I understood, I was ashamed. It was embarrassing kind of thing.' Father

Feelings of anger, shock, confusion, humiliation, embarrassment and shame created feelings of hostility towards professionals and early interactions with professionals were described as antagonistic. Akin to the findings of others, parents were aware and wary of the powers of social workers to remove children (Smithson \& Gibson, 2014). Parents described that this made them desperate to work out 'what they had to do', or to conceal problems. Most reported feelings of hate, anger and rage towards professionals at this stage. 
While authors such as Tuck (2013) have highlighted that 'hostility is not unchangeable' but can shift as a consequence of skilled professional engagement, the psychosocial 'state' of parents in these circumstances has received little attention. Tuck (2013:9) argues that there has been a lack of recognition of 'parental 'damage'. The interaction between intervention trauma, unresolved traumas and other chronic stressors, can create intransigent parental responses and a challenging context for professional engagement (Walker, 2007).

The reasons for intervention were not well understood by parents during the early stages. In particular, parents were confused about what was meant by children being placed on the child protection register, the reasons for registration and the implications of this:

'I didn't understand it all how they got on the register. What is the register? It was a long time ago...so I didn't understand....it didn't feel real to me... when I understood, I was ashamed. It was embarrassing kind of thing.' Father

The exception to these accounts was the narrative of the Grandfather within the study. This grandfather described how he had sought the support of child protection services because he had concerns about the welfare of his grandchildren. This grandfather's narrative is important insofar as it communicates that child protection services are identified as a source of help and support where family members have concerns about the welfare of children within the family. 


\section{Developing Understanding}

Four parents appeared to have remained confused about the reasons for involvement or disagreed with the actions that had been taken throughout the processes they had experienced. The narratives of these parents suggested that they held and had retained different ideas about acceptable levels of care, home conditions and issues of risk to their children. One father expressed his disagreement with professional assessments of children as being at risk and said:

'My kids were always safe.' Father

A mother who had relocated from another local authority considered that professional concerns about the living conditions within her home being unsuitable for children had been unfair. She talked about how they had not long relocated at the point of intervention and that social workers had not given them a chance of bring order their home:

'Everything happened too fast...we didn't have enough time to get the house organised.' Mother

One of the couples interviewed communicated a retained belief that the primary reason for intervention was the persistence of head lice amongst their children. They believed this to the reason for registration and were persistent in expressing this view to the interviewer. Statements such as these revealed conflicts between parents and professionals around issues of care and risk to children. While these conflicts were discussed, there was little evidence within our data about how parents and professionals negotiated these. 


\section{Understanding Interventions and Actions}

Confusion or disagreement around the grounds for intervention persisted for some parents. However, where this was evident there was a simultaneous - although at times rudimentary understanding of the role of the child protection services and the aims and objectives of intervention. Most of the parents described a developing understanding of the reasons for intervention. Moreover, most conceded in their accounts that they considered professional action to have been necessary. Understanding what was going on appeared to be a process which unfolded overtime. Parents articulated that professionals had helped them develop this understanding. Hence:

'It can take a while to understand but she was good she was [social worker] at telling us.' Mother

Participant accounts revealed good practices around the provision of information and explanation of processes which, is considered necessary to facilitate participation. Parents talked about professionals taking care to explain the reasons for intervention, actions and processes. Information was also provided in appropriate formats which took into account the particular needs of individuals:

'You always get information sent out about the decisions made at meetings...you get information about the meeting beforehand.' Father

Most parents also said that professionals were also good at explaining what was going on, what was likely to happen at meetings and the reasons for decisions:

'They always told me what was going on. They always told me what was happening. $\mathrm{X}$ [social worker] would come out before and sit and go through it with me.' Mother 
Statements such as these evidenced conscientious efforts by professionals to ensure that effective communication did occur. Moreover, some participants who had particular learning disabilities discussed receiving information in formats that they could understand. However, the extent to which parents understood the reasons for professional planning and intervention varied quite considerably even where efforts had made to explain decisions. This suggests that even where best efforts were made to communicate with parents around such issues this did not always result in understanding. However, some parents were able to clearly articulate the reasons for actions within plans and the longer term objectives that were working towards. A particularly notable example of this was the couple with learning difficulties who were very clear in their explanation of why intervention had occurred, the purpose of the supports they were receiving and the longer term aims of intervention. Others were more ambivalent in their responses stating that they sometimes understood what was going and other times they did not.

\section{Relationships with Professionals}

In our study, as in others, practitioners had to create relationships in circumstances where parents were emotionally vulnerable, volatile and antagonistic towards professionals and this is recognised as considerably challenging (Slettebo, 2013). The findings of this study suggest that the particular professionals working with the parents in our sample were extremely skilled in doing so. In reflecting upon their early relationships with professionals, parents frequently recalled their initial hostilities toward professionals. The early stages of intervention have been theorised as being about the use and negation of power and identity through dialogical exchange in relational work between service users and professionals (Hall et al., 2006). Forrester et al., (2008) suggests that effective intervention in child protection is 
more likely to happen when professionals can, within the context of relational work, skilfully balance the care aspects of their work with the control functions. Here, it is argued that professionals who invoke or draw on power whilst simultaneously exhibiting high levels of empathy with service users are likely to be most effective at engaging families in processes of change. Parental narratives indicated that successful intervention, wherein they defined the outcomes of intervention as having made a positive difference, appeared to be intimately connected to the development of relationships between professionals and parents that were characterised by 'therapeutic' dimensions. There exists evidence to suggest that the presence or absence of therapeutic qualities and associated communication skills such as 'listening' and 'understanding' determines to some extent whether the outcomes of intervention are successful or not (Lishman, 1988).

Parents communicated these 'therapeutic dimensions' through constructs of professionals as 'helpers' or 'supporters' who had particular personal qualities as 'listeners' or 'confidants' that is, as 'someone you could talk to' or 'who understood':

They really do understand [social work]. X [social worker] she really bends over backwards to help us with everything she can the same with $\mathrm{x}$ [different social worker]. We have had great support.' Father

And:

'When I talk to a worker - whatever one it is - the ones who come in during the day or I can pick up the phone - whatever one it is, depends what time of the day I am having the problem - I can bounce things off them, I can talk it about it, bounce it off them, it is kind of 
like counselling and they can take what they say and bounce it back to you.' Mother

Parents were surprisingly positive in discussing their relationships with social workers given the level of distress that they reported in relation to some aspects of experience and also because most other studies also report more variation. What is clear however is that these relationships took time, effort and commitment to develop.

\section{Child Protection Case Conferences}

Attendance at case conferences, particularly initial and early case conferences, has frequently been reported in the findings of studies as distressing, intimidating, humiliating, frightening and disempowering experiences for parents (Buckley et al., 2011; Dale, 2004; Healy et al., 2012). Our findings resonate strongly with these observations. Akin to the findings of others, parents were intimidated by the large number of professionals in attendance and experienced the quasi-legal discursive practices which framed these meetings as intimidating and marginalising (Healy et al., 2011 \& 2012; Buckely, et al., 2011; Dale, 2004; Prince et al., 2005; Thomson \& Thorpe, 2004). While parents fundamentally understood the functions of the case conference at the time of interview and discussed being informed about the nature and structure of case conferences, they also reported that this did not prepare them for the emotional impact of attendance:

'The very first meeting now I am talking there were three desks all lined up and there were folk all the way round it. There were police everything, teachers, social workers all in a row...it was scary, really really scary. The only person I knew, I didn't even know my drug 
worker then either. The only person I knew was $\mathrm{x}$ [social worker] and $\mathrm{x}$ [social worker] and the head teacher from the school that was it. I just lost the head.' Mother

Parents did report that their views were sought in these meetings but most felt that it was difficult to express these and respond to professional opinions because they were often not consulted until after every other professional had contributed. In such instances, parents found it difficult to respond because they found it difficult to recall what professionals had said. They also reported that they found it difficult to challenge professionals in such settings especially where facts were in dispute.

Two participants mentioned the value of hearing professional views on the progress of children. The grandfather in the sample experienced case conferences positively in this respect although he conveyed that he did not always feel that the information shared was accurate. One father also mentioned that he found these aspects useful but that he would have appreciated a more positive approach to parenting issues:

'I do appreciate the feedback at the meetings. I like to hear opinions about how the kids are getting on...but I think it should be more trying to encourage and saying look listen you know yourself you have done wrong the only thing you can do is try to make it better instead of being a failure as a parent.' Father

Other researchers who have discussed similar parental experiences of case conferences suggest that these kinds of narratives are indicative of authoritarian approaches to practice 
(Featherstone et al., 2014; Parton, 2014). Moreover, it has been highlighted that the emotional distress that parents experienced during these settings substantially reduces their capacity for active participation in the decision making processes of case conferences (Smithson \& Gibson, 2016). Within our study parents clearly did not articulate participatory experiences. More crucially, a few parents fundamentally considered that decision making powers resided with the chairperson who was often referred to in terms conferring this status. The chairperson was often given labels by parents such as 'the big boss', 'the big man' and so forth. Hence, some parents did not conceptualise the decision making process as democratic. It is noteworthy however, that in discussing case conferences, parents were generally complimentary about their social workers and other professionals they worked with on an individual basis and often made a point of highlighting that it was the process of the case conference that was problematic and not the individual professionals in attendance.

\section{Discussion}

\section{Making a Difference}

Studies report that despite a range of negative experiences some parents consider that statutory child protection intervention makes a positive difference to their lives (Dale, 2004). To the credit of the local authority being studied and those social workers who had worked with the parents we interviewed, there was consensus amongst parents that professional intervention had ultimately been 'good thing' that had a 'made a difference':

'If social work had not been involved things would have been the same. The wee ones getting taking off us basically was a real culture shock. That's when I went what am I doing? I need to turn my life 
around. I couldn't live with myself if my wee ones had to grow up in foster care...it was a shock.' Father

Indeed, parents felt that their family lives had improved, that their children were doing better and that they were becoming better parents. Some also felt that their children were safer because of intervention. There was also a tendency to speak with pride about the process of change they had experienced and how the supports they received had helped them accomplish change. Their narratives of change and their assessment that intervention had made a positive difference, despite the various distresses they experienced, suggest that skilful and meaningful engagement work had taken place and empowered these parents to actively participate in a process of meaningful transformation.

In the context of this study, as in others, relationships with professionals appeared deeply connected to positive outcomes. Empirically, however, we cannot account for what professionals actually did to achieve these outcomes or identify their methodologies. Moreover, although the link between relationships with professionals and outcomes has been established, and theorised as being anchored in discursive practices (Howe, 1998), more widely there is a recognition that we know very little about how child protection is performed in the relational dynamics that take place between professionals and service users (Ferguson, 2009). Others have argued that ways in which professionals work with power are central to shaping parental responses to intervention. Dumbrill (2006) for instance, argues that parents who perceive professionals using their power 'with' them rather than 'over' them are more likely to work in partnership. Dumbrill (2006) cautions however that it is difficult to explain this through 'worker style' as the same professionals can be simultaneously perceived as 
using different practice styles by different parents. However, the perception that power is used constructively appears to be important.

Although our sample is small and speaks to the experiences of parents within one local authority in Scotland, our substantive findings are strongly similar to both past and recent studies in this area across the UK and internationally. That said, the overall outcomes of the process of intervention alongside views of professionals were markedly more positive. How can we account for this? One possible explanation is that our sample was not representative. This is highly likely given the sampling issues we experienced and it is possible that parents who participated felt more empowered or less threatened to do so because they had experienced good outcomes and were progressing. Tentatively, we could also suggest that perhaps modes of practice within our study site were more participative in orientation than in others. Indeed, studies have noted that there can be regional variations in modes of practice (Thorburn, et al., 1995). The more troubling issue in the observation above is that it raises a number of questions about why, despite several decades of evidence, there has not been a more fundamental shift towards changing those elements of the system that are experienced as dehumanising and distressing.

Clearly, it is difficult to completely eliminate practices that are experienced as distressing and traumatic for parents given the nature of child protection concerns and the inherent conflicts that are intrinsic in this area of practice (Bell, 1999). Neither should we lose sight of the fact that the fundamental purpose of the child protection system is about protecting children from serious harm (Smithson \& Gibson, 2016). Nonetheless, considering the refocusing on 
relationship based practice with the UK more broadly (Munro, 2011) there is perhaps scope to reconsider process aspects which negatively influence the conditions for engagement with parents and /or inhibit their participation.

While we found that professionals generally took care to communicate with parents, explain decisions and processes and provide information, there is scope to more thoroughly consider practices with parents during the early stages of intervention. Whether due to heightened emotional distress or their unfamiliarity with the process, parents appear to lack an adequate understanding of professional concerns and the reasons for intervention. That said, professionals were clearly skilled in working with parents to move them towards a more informed and meaningful trajectory. Understanding more thoroughly how this is achieved in practice would also be beneficial.

Far from evoking any sense of meaningful participation in decision making, case conferences seemed to be characterised by authoritarian practices which excluded parents from contributing in significant ways. Case conferences have been consistently reported for several decades as traumatic and exclusionary rather than participatory yet, research does not appear to have effected change. Again, there were efforts by professionals to prepare parents for case conferences however this did little to equip them emotionally and they did not feel empowered to contribute meaningfully. Parents had some simple and practical suggestions for improving their experience. They suggested that changes to the courtroom style of meeting rooms would reduce feelings of intimidation as would having professionals enter the conference after them. Being able to respond to the individual commentaries of different 
professionals was suggested as a method that would enable more effective parental contributions.

\section{Conclusion}

Understanding how parents experience statutory child protection intervention is important for professionals, agencies and policy makers to enable services to develop intervention practices that create the conditions for constructive engagement, meaningful participation and positive outcomes for both parents and children (Dumbrill, 2006). The purpose of this study was to inform the development of services within one local authority in Scotland and to provide parents with the opportunity to influence the future shape of services. The parents we interviewed clearly articulated that they had participated in this study because they wanted to share their experiences in the hope that it might lead to better experiences for others. Notably, they also wanted to express their view that professional intervention can help, and that as a consequence family life can take on a more positive trajectory. For a profession that is often negatively portrayed, these are positive messages. 


\section{References}

Asquith, S., Clark, C., \& Waterhouse, L., (2005). The Role of the Social Worker in the $21^{\text {st }}$

Century: A Literature Review. The Scottish Government, Edinburgh. Available Online at: http://www.gov.scot/Publications/2005/12/1994633/46334

Barford, R. (1993). Children's Views of Child Protection Social Work. University of East Anglia: Norwich.

Bosk, C. (2002). Obtaining voluntary consent for research in desperately ill patients. Medical Care, 40(9) Supplement: V-64-V-68.

Barford R., \& Wattam, C. (1991). Children's participation in decision making. Practice, 5: 93-102.

Begum, N. (2006). Doing it for themselves: participation and black and minority ethnic service users. Social Care Institute for Excellence and the Race Equality Unit.

Bell, M. (1999). Working in partnership in child protection: The conflicts, British Journal of Social Work, 29: 437-455.

Bilson, A. (2002). Family support: Messages from research. Representing Children, 15(1): $10-20$.

Bruan, V., \& Clarke, V., (2006). Using thematic analysis in psychology. Qualitative Research in Psychology, 3: 77-101.

Buckley, H., Carr., \& Whelan, S. (2011). 'Like walking on eggshells': service user views and expectations of the child protection system, Child and Family Social Work, 16: 101-110. 
British Association of Social Works (2012/14). The Code of Ethics for Social Work: Statement of Principles 2012. BASW: Birmingham. Published online at: https://www.basw.co.uk/codeofethics/

Bulmer, M. (2008). 'The ethics of social research', In Gilbert, N. (Ed). Researching Social Life, $3^{\text {rd }}$ Edition. London: Sage, pp.145-162.

Cooper, A., Katz, I., \& Hetherington, R. (2003). The Risk Factor: Making the Child Protection System Work for Children. Demos: London. Published online at: http://www.demos.co.uk/files/The_Risk_Factor.pdf

Corby, B., Millar, M., \& Young, L. (1996). Parental participation in child protection work: rethinking the rhetoric, British Journal of Social Work, 26: 475-492.

Dale, P. (2004). 'Like fish in a bowl': Parental perceptions of child protective services, Child Abuse Review, 13(2): 137-157.

Davies, P. (2011). The impact of a child protection intervention: A personal reflective account, Child and Family Social Work, 15: 201-209.

Dumbrill, G. (2006). Parental experience of child protection intervention: a qualitative study, Child Abuse \& Neglect, 30: 27-37.

Featherstone, B., Morris, K., \& White, S. (2014). Re-imagining Child Protection: Towards Humane Social Work with Families. London: Policy Press.

Ferguson, H. (2009). Performing child protection: home visiting, movement and the struggle to reach the abused child. Child and Family Social Work, 14:471-480.

Fisk, M. \& Wigley, V. (2000). Accessing and interviewing the oldest old in care homes. Quality in Ageing, 1(1):27-33. 
Forrester, D., Kershaw, S., Moss, H., \& Hughes, L. (2008). Communication skills in child protection: How do social workers talk to parents?, Child and Family Social Work, 13(1): 4151.

French, J., \& Raven, D. (1959). The bases of social power. In: Cartwright, D. (ed.) Studies in Social Power. Ann Arbour: University of Michigan Press.

Gallagher, M., \& Smith, M. (2010). Engaging with voluntary service users in social work: literature review 1: context and overview, University of Edinburgh, Published online at: http://www.socialwork.ed.ac.uk/_data/assets/pdf_file/0016/44224/review_1_context_and_o verview.pdf

Hall, C., Slembrouck, S., \& Saranagi, S. (2006). Language Practices in Social Work: Categorisation and Accountability in Child Welfare. Abingdon: Routledge.

Healy, K., \& Darlington, Y. (2009). Service user participation in diverse child protection contexts: principles for practice. Child \& Family Social Work, 14(4), 420-430.

Healy, K., Darlington, Y., \& Feeney, J.A. (2011). Parents' participation in child protection practice: Toward respect and inclusion. Families in Society. The Journal of Contemporary Social Services, 92(3):282-288.

Healy, K., Darlington, Y., \& Yellowlees, J. (2012). Family participation in child protection practice: an observational study of family group meetings. Child and Family Social Work, 17:1-12.

Howe, D. (1998). Relationship based thinking and practice in social work. British Journal of Social Work, 12(1): 45-56. 
International Federation of Social Wokers (2004). Statement of Ethical Principles. Available online at: http://ifsw.org/policies/statement-of-ethical-principles/

Kadushin, A., \& Kadushin, G. (1997). The Social Work Interview: A Guide for Human Service Professionals. New York: Columbia University.

Lee, R. (1993). Doing Research on Sensitive Topics. London: Sage.

Liamputtong, P. (2007). Researching the Vulnerable: A Guide to Sensitive Research Methods. London: Sage.

Lishman, J. (1988). Social work interviews: how effective are they?, Research, Policy and Planning, 5: 1-5.

Maiter, S., Palmer, S., \& Manji, S. (2006). Strengthening social worker - client relationships in child protective services: Addressing power imbalances and ruptured relationships, Qualitative Social Work, 5(2): 161-186.

Munro, E. (2011). The Munro Review of Child Protection: Final report-a child-centred approach (Vol. 8062). The Stationery Office.

Parton, N. (2014). The Politics of Child Protection: Contemporary Developments and Future Directions. London: Palgrave Macmillan.

Prince, J., Gear, A., Jones, C., \& Read, M. (2005). The child protection conference: a study of process and an evaluation of the potential for online group support. Child Abuse Review, 14:113-131.

Ryburn, M. (1997). Dilemmas in working in partnership with parents and relatives of children involved in child protection planning. Early Child Development and Care, 129: 7993. 
Saint-Jacques, M. C., Drapeau, S., Lessard, G., \& Beaudoin, A. (2006). Parent involvement practices in child protection: A matter of know-how and attitude. Child and Adolescent Social Work Journal, 23(2), 196-215.

Scottish Government (2014). National Guidance for Child Protection in Scotland 2014.

Edinburgh: Scottish Government. Published at: http://www.gov.scot/Publications/2014/05/3052/0

Sensing, T. (2011). Qualitative Research: A Multi-Methods Approach to Projects for Doctor of Ministry Thesis. Eugene, OR: Wipf \& Stock.

Slettebo, T. (2013). Partnership with parents of children in care: a study of collective user participation in child protection services. British Journal of Social Work, 43: 579-595.

Smithson, R., \& Gibson, M. (2016). Less than human: a qualitative study into the experience of parents involved in the child protection system. Child and Family Social Work, Early View Article. Available online at: http://onlinelibrary.wiley.com/doi/10.1111/cfs.12270/pdf

Thorburn, J., Lewis, A., \& Shemmings, D. (1995). Paternalism or Partnership: family involvement in the child protection process. London: HMSO

Thomson, J., \& Thorpe, R. (2004). Powerful partnerships in social work: groupwork with parents of children in care. Australian Social Work, 57: 46-56.

Trotter, C. (2002). Worker skill and client outcome in child protection, Child Abuse Review, 11(1): 38-50.

Tuck, V. (2013). Resistant parents and child protection: knowledge base pointers for practice and implications for policy, Child Abuse Review, 22: 5-19. 
Walker, J. (2007). Unresolved loss and trauma in parents and the implications for child protection, Journal of Social Work Practice, 21(1): 77-87.

Warren, C. (2002). 'Qualitative interviewing', In Gubrium, J., \& Holstein, J. (Eds.) Handbook of Interview Research: Context and Method. Oaks, CA: Sage, pp.83-101.

Warren, J. (2007). Service user and carer participation in social work, Learning Matters: Exeter.

Woolfson, R., Heffernan, E., Paul, M., \& Brown, M. (2010). Young people's views of the child protection system in Scotland, British Journal of Social Work, 40(7): 2069-2085.

Wrennall, L. (2010). Surveillance and child protection: demystifying the Trojan horse, Surveillance and Society, 7(3/4): 304-324. 